\title{
RRNPP-type quorum-sensing
} systems regulate solvent formation, sporulation and cell motility in Clostridium saccharoperbutylacetonicum

\author{
Jun Feng ${ }^{1}$, Wenming Zong ${ }^{1,2}$, Pixiang Wang ${ }^{1}$, Zhong-Tian Zhang ${ }^{1}$, Yanyan Gu' ${ }^{1}$, Mark Dougherty ${ }^{1}$, llya Borovok ${ }^{3 *}$
} and Yi Wang ${ }^{1,4^{*}}$ (D)

\begin{abstract}
Background: Clostridium saccharoperbutylacetonicum N1-4 (HMT) is a strictly anaerobic, spore-forming Gram-positive bacterium capable of hyper-butanol production through the well-known acetone-butanol-ethanol fermentation process. Recently, five putative RRNPP-type QSSs (here designated as QSS1 to QSS5) were predicted in this bacterial strain, each of which comprises a putative RRNPP-type regulator (QssR1 to QssR5) and a cognate signaling peptide precursor (QssP1 to QssP5). In addition, both proteins are encoded by the same operon. The functions of these multiple RRNPP-type QSSs are unknown.

Results: To elucidate the function of multiple RRNPP-type QSSs as related to cell metabolism and solvent production in N1-4 (HMT), we constructed assR-deficient mutants $\triangle R 1, \triangle R 2, \triangle R 3$ and $\triangle R 5$ through gene deletion using CRISPRCas9 and N1-4-dcas9-R4 (with the QssR4 expression suppressed using CRISPR-dCas9). We also constructed complementation strains by overexpressing the corresponding regulator gene. Based on systematic characterization, results indicate that QSS1, QSS2, QSS3, and QSS5 positively regulate the sol operon expression and thus solvent production, but they likely negatively regulate cell motility. Consequently, QSS4 might not directly regulate solvent production, but positively affect cell migration. In addition, QSS3 and QSS5 appear to positively regulate sporulation efficiency.

Conclusions: Our study provides the first insights into the roles of multiple RRNPP-type QSSS of C. saccharoperbutylacetonicum for the regulation of solvent production, cell motility, and sporulation. Results of this study expand our knowledge of how multiple paralogous QSSs are involved in the regulation of essential bacterial metabolism pathways.
\end{abstract}

Keywords: Clostridium saccharoperbutylacetonicum, Butanol, Acetone-butanol-ethanol (ABE), RRNPP-type quorumsensing systems, Signaling peptide precursor, Cell motility, Sporulation, CRISPR-Cas9

*Correspondence: ilyabo@tauex.tau.ac.il; yiwang3@auburn.edu ${ }^{1}$ Department of Biosystems Engineering, Auburn University, 350 Mell Street, Auburn, AL 36849, USA

${ }^{3}$ School of Molecular Cell Biology and Biotechnology, The George S. Wise Faculty of Life Sciences, Tel Aviv University, Ramat Aviv, 6997801 Tel Aviv, Israel

Full list of author information is available at the end of the article

\section{Introduction}

Quorum-sensing allows bacterial cells to regulate gene expression in response to the variation in cell-population density. Bacterial cells produce extracellular chemical signals (small molecules or peptides), which could accumulate in a local environment to critical levels and thereby regulate expression of specific pathways in response to

(c) The Author(s) 2020. This article is licensed under a Creative Commons Attribution 4.0 International License, which permits use, sharing, adaptation, distribution and reproduction in any medium or format, as long as you give appropriate credit to the original author(s) and the source, provide a link to the Creative Commons licence, and indicate if changes were made. The images or other third party material in this article are included in the article's Creative Commons licence, unless indicated otherwise in a credit line to the material. If material is not included in the article's Creative Commons licence and your intended use is not permitted by statutory regulation or exceeds the permitted use, you will need to obtain permission directly from the copyright holder. To view a copy of this licence, visit http://creativeco mmons.org/licenses/by/4.0/. The Creative Commons Public Domain Dedication waiver (http://creativecommons.org/publicdomain/ zero/1.0/) applies to the data made available in this article, unless otherwise stated in a credit line to the data. 
population density [1-3]. Both Gram-positive and Gramnegative bacteria have been reported to use quorum sensing for communication to regulate various physiological activities. However, the mechanisms for quorum sensing in Gram-positive and Gram-negative bacteria are usually different. In general, Gram-negative bacteria use acylated homoserine lactones as autoinducers for quorum sensing, while Gram-positive bacteria use processed oligo-peptides to communicate with each other $[4,5]$. It is essential to elucidate the effects of quorum-sensing systems (QSSs) in the bacterial host in order to understand the social biology of the bacteria, treat the relevant infectious diseases, and enhance the production of desirable metabolites.

Acetone-butanol-ethanol (ABE) fermentation with solventogenic clostridia has been a well-known industrial process since the early twentieth century. The ABE fermentation has two phases, acidogenesis and solventogenesis [6, 7]. During the acidogenesis phase, fatty acids including acetic acid and butyric acid are synthesized to maximize ATP generation to support active cell growth. With continuous accumulation of fatty acids, extracellular acids will diffuse back into cells, which may inhibit cell metabolism and cause acid crash. To avoid such an outcome, the cell will switch metabolism from acidogenesis to solventogenesis during which acids are re-assimilated and solvents (ABE) are produced $[7,8]$. However, the mechanism to shift metabolism from acidogenesis to solventogenesis is not well understood. Nevertheless, tremendous efforts have been invested by researchers to improve solvent production in various solventogenic clostridial strains through metabolic engineering [9-11]. However, limited success has been achieved so far, largely due to our poor understanding of the regulation of cell metabolism, especially as it relates to solvent production.

To date, there are only a small number of reports concerning QSSs in solventogenic clostridial species [7, 12, 13]. There are two main types of QSSs in solventogenic clostridia: the $a g r$-like [12, 14] and the RRNPP-type [13]. The agr (accessory gene regulator) system was first discovered in Staphylococcus [15] and is controlled by an auto-inducing peptide (AIP). AIP is synthesized and secreted during cell growth and activates specific gene expression when accumulated to certain levels. The core mechanism for the production and sensing of AIP is accomplished by genes organized in the agrBCDA operon. When extracellular AIP accumulates to certain concentrations, it will be sensed by the histidine kinase AgrC, resulting in the phosphorylation of the response regulator AgrA. Subsequently, the phosphorylated AgrA will regulate the expression of target genes or pathways $[16,17]$. The RRNPP (formerly known as RNPP) QSSs were named after the well-studied peptide-sensing regulatory proteins: $\underline{\mathbf{R}} \mathrm{p}, \underline{\mathbf{R} g g}, \underline{\mathbf{N} p r R}, \underline{\mathbf{P}} \mathrm{lcR}$, and $\underline{\operatorname{PrgX}})$ $[5,18,19]$. Phylogenetic analysis suggested that all regulatory proteins were derived from a common ancestor and in fact form a single family with conserved features [20]. RRNPP family members are characterized by the presence of tetratricopeptide repeats (TPRs) that are responsible for promoting protein-protein (more specifically, protein-peptide) interactions [20, 21]. RRNPP-type QSSs comprised quorum-sensing regulators and cognate signaling peptides. These two above components can directly interact with each other and regulate relevant cell metabolism. The signaling peptide, which is derived from the C-terminus of the signaling peptide precursor through proteolysis during secretion, is imported into the cell again by the oligopeptide permease (Opp) transport system. The mature signaling peptide can interact with the regulator protein, thereby activating or inhibiting relevant cell metabolism.

Both the agr-and RRNPP-type QSSs have been investigated in $C$. acetobutylicum, the model microorganism for ABE fermentation. In 2012, Steiner and co-workers observed that the arg QSS participated in the regulation of sporulation and granulose formation in C. acetobutylicum [12]. Recently, the same group studied multiple RRNPP-type QSSs in C. acetobutylicum using ClosTron for inactivation of genes encoding these systems [13]. Their results suggested that seven of the eight RRNPPtype QSSs (QssA-H) affected solvent formation, and it was inferred that QssB was involved in the regulation of sporulation and early solventogenesis. Interestingly, both types of QSSs (agr and RRNPP) in various solventogenic clostridial strains are encoded by multiple genomic loci, leaving many questions regarding their cooperation and co-regulation.

Clostridium saccharoperbutylacetonicum N1-4 (HMT) is well-known as a hyper-butanol producer [22]. In 2007, Kosaka and co-workers speculated that a QSS might be participating in regulation of the solvent metabolism of N1-4 (HMT) [7]. Recently, Kotte and co-workers predicted multiple QSSs in C. saccharoperbutylacetonicum while primarily investigating RRNPP-type QSSs in $C$. acetobutylicum [13]. The elucidation of QSSs function in N1-4 (HMT) is highly desirable for understanding the mechanism of solventogenesis and further improving host solvent production through metabolic engineering. Due to the lack of highly efficient genetic engineering tools, it was not possible to conduct an in-depth QSSs investigation nor the relevant strain regulatory mechanisms. Recently, our group has developed highly efficient genome editing tools for the N1-4 (HMT) strain based on the CRISPR-Cas9 system [23]. With these versatile genetic tools, the RRNPP-type QSSs in N1-4 (HMT) were systematically investigated through precise and clean gene 
deletion. Our study revealed for the first time that multiple RRNPP-type QSSs of C. saccharoperbutylacetonicum play important roles in solvent production, cell motility, and sporulation. Moreover, the results of this study expand our knowledge about the function of bacterial QSSs related to essential pathways of cellular metabolism.

\section{Results and discussion}

\section{Construction of mutant strains}

Recently, multiple RRNPP-type QSSs in C. acetobutylicum ATCC 824 have been characterized by Kotte and co-workers [13]. The function of these QS systems was investigated through the insertional inactivation of the corresponding regulator gene using ClosTron technology [13]. The eight RRNPP-type QSSs (QssA to QssH) have been reported to play important roles in the life cycle of C. acetobutylicum ATCC 824. Interestingly, no such similar QSSs have been identified in another prominent ABEproducing strain, C. beijerinckii NCIMB 8052; while in $C$. saccharoperbutylacetonicum N1-4 (HMT), five putative RRNPP-type QSSs have been predicted [13]. Thus, in this study we aimed to elucidate the function of these QSSs in C. saccharoperbutylacetonicum as related to its hyperbutanol production phenotype.

Figure 1 shows the arrangement of all five predicted RRNPP-type QSSs within the N1-4 (HMT) genome, designated as QSS1, QSS2, QSS3, QSS4, and QSS5, respectively. As in the case of $C$. acetobutylicum, each RRNPP-type QS system in N1-4 (HMT) comprises two predicted functional protein units: an RRNPP regulator (QssR1, QssR2, QssR3, QssR4, or QssR5) and a putative cognate signaling peptide precursor (QssP1, QssP2, QssP3, QssP4, or QssP5).

To elucidate the function of RRNPP-type QS systems in N1-4 (HMT), their regulator genes were deleted using the CRISPR-Cas9 system recently developed in our lab [23]. Four of the five qssR genes (qssR1, qssR2, qssR3, and qssR5) were successfully deleted (Additional file 1: Figure $\mathrm{S} 2$ ), and the resulting mutants were designated as $\Delta \mathrm{R} 1$, $\Delta R 2, \Delta R 3$ and $\Delta R 5$, respectively. Interestingly, we failed to delete qssR4 (Cspa_c29260) despite multiple attempts using different gRNAs and homology arms of various lengths (data not shown). In order to study the function of QssR4, a CRISPR-dCas9 vector was constructed and employed to inhibit the expression of qssR4. The resulting strain was named N1-4-dcas9-R4 [24]. There are two genes immediately downstream of the qssR4-qssP4 locus, the proximal one is noted as phosphopantetheineprotein transferase (Cspa_c29240), while the distant one encodes a putative oleoyl-(acyl-carrier-protein) hydrolase (Cspa_c29230). The homologues of these enzymes are reported to participate in fatty acid biosynthesis [25, 26]. Therefore, we hypothesize it is likely that QSS4 plays an essential role in regulation of the fatty acid biosynthesis pathway and/or other crucial metabolic pathways in C. saccharoperbutylacetonicum. It is for this reason that qssR4 cannot be deleted.

\section{Complementation of the $q s s R$ gene function}

To better understand the regulatory role of RRNPP-type QSSs, we overexpressed the individual $q s s R$ gene on a plasmid in the corresponding qssR-deleted mutant thus fulfilling the complementation of a gene deletion. The $q s s R$ gene expression was driven by the cat1 gene promoter from C. tyrobutyricum ATCC 25755 [27] and carried on the plasmid pMTL82151. The recombinant plasmid construct was transformed into the corresponding qss $R$-gene-deleted mutant, thus generating a set of four strains $(\Delta \mathrm{R} 1-\mathrm{R} 1, \Delta \mathrm{R} 2-\mathrm{R} 2, \Delta \mathrm{R} 3-\mathrm{R} 3$, and $\Delta \mathrm{R} 5-\mathrm{R} 5)$. Moreover, the pMTL-qssR4 plasmid (qssR4 under control of the cat1 promoter) was transformed into the wild-type (WT) N1-4 (HMT) strain to investigate the possible effect of qssR4 overexpression as a function of WT phenotype.

The expression of qss $R$ genes in various recombinant strains compared to WT phenotypes was investigated in three different media, P2, TGY and PG (Additional file 1: Figures S3-S5). Overall, results indicated that the medium had little impact on gene expression trend (that is, the relative expression (higher or lower) in the recombinant strain compared to that in WT), but had a significant impact on absolute expression levels of the particular $q s s R$ gene. Briefly, the expression levels of qssR1, qssR2, qssR4 and qssR5 in strains $\Delta \mathrm{R} 1-\mathrm{R} 1, \Delta \mathrm{R} 2-$ $R 2, N 1-4-R 4$ and $\Delta R 5-R 5$, respectively, were all higher than those in the WT strain. For instance, expression of qssR1 in $\Delta \mathrm{R} 1-\mathrm{R} 1$ was increased by 287 - to 560 -fold over WT depending on different media (Additional file 1: Figures S3-S5). Interestingly, the increase in expression level of qssR2 in $\Delta \mathrm{R} 2-\mathrm{R} 2$ (compared to that in WT) varied remarkably in different media, by 49 -fold in $\mathrm{P} 2$ medium (Additional file 1: Figure S3), 775-fold in PG medium (Additional file 1: Figure S5), and 25,260-fold in TGY medium (Additional file 1: Figure S4). While for qssR4 and $q s s R 5$, the increase in expression levels (in strains N1-4-dcas9-R4/pMTL-qssR4 and $\Delta$ R5-R5, respectively) was only several fold (less than ninefold) in all the media (Additional file 1: Figures S3-S5). On the other hand, the expression level of qssR3 was lower in $\Delta \mathrm{R} 3-\mathrm{R} 3$ than in the WT (from 5.4 to $46 \%$ less). Possibly, the native promoter of $q s s R 3$ is much stronger than the cat1 promoter that was used for the complementation expression. Results also indicated that the CRISPR-dCas9 system functioned well with the N1-4-dcas9-R4 strain. The qssR4 expression was inhibited $89.8 \%$ in P2 medium, $54.3 \%$ in TGY medium and $86.4 \%$ in PG medium, respectively, as compared to that in WT (Additional file 1: Figures S3-S5). 
a

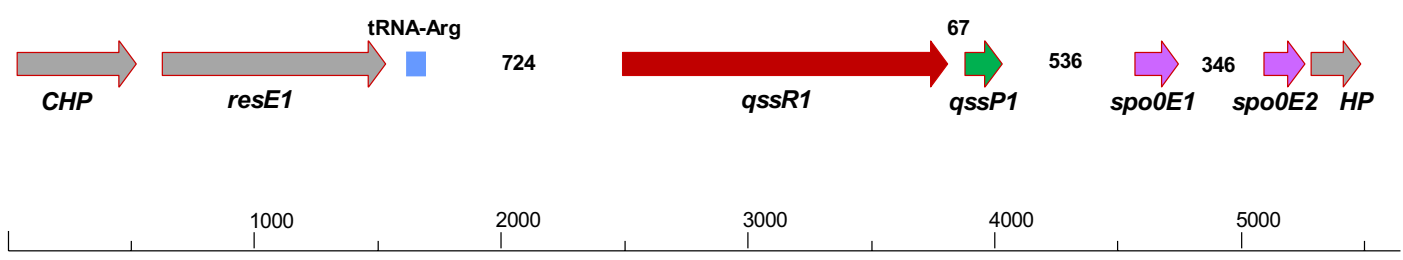

b
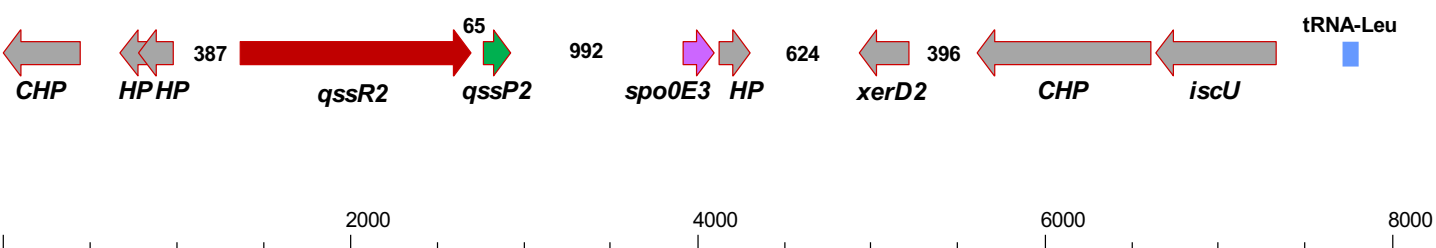

c

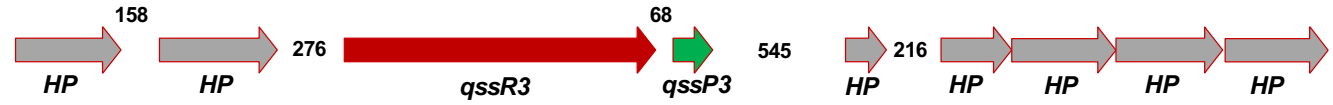

1000

2000

3000

4000

5000

d

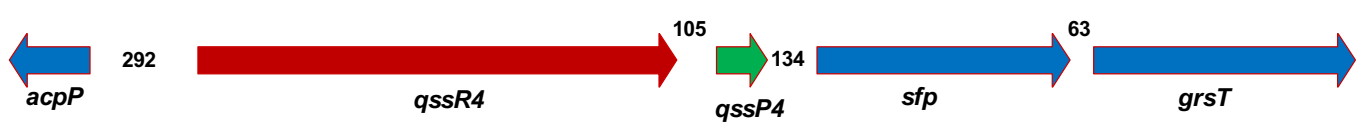

$\begin{array}{lll}1000 & 2000 & 3000\end{array}$

e

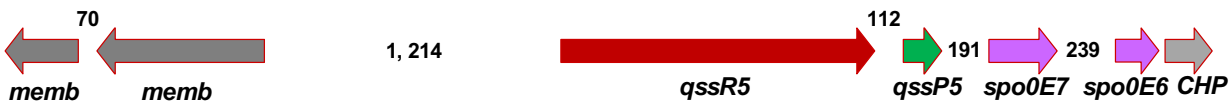

1000

2000

3000

4000

5000

Fig. 1 Schematic representation of the five genomic regions encoding putative RRNPP-type quorum-sensing systems in Clostridium saccharoperbutylacetonicum N1-4 (HMT). Genomic regions were designated as QSS1 (a), QSS2 (b), QSS3 (c), QSS4 (d) and QSS5 (e), respectively. Gene names are the following: HP, hypothetical protein; CHP, conserved hypothetical protein; memb, membrane-associated protein; spoOE, Spo0E-like sporulation regulatory protein; qssR1-5, putative RRNPP-type regulator (QssR1 to QssR5); qssP1-5; cognate signaling peptide precursor (QssP1 to QsSP5); resE1, sensor histidine kinase ResE; xerD2, site-specific recombinase XerD; iscU, NifU-like protein involved in Fe-S cluster formation; acpP, acyl carrier protein; sfp, phosphopantetheine-protein transferase; grsT, oleoyl-(acyl-carrier-protein) hydrolase. The number indicates the nucleotide base pairs between two genes. The arrows in red represent the genes that have been deleted in this study

\section{RRNPP-type QSSs regulate solvent formation}

In order to investigate the effect of RRNPP-type QSSs on solvent production in C. saccharoperbutylacetonicum, fermentations were first carried out in small-scale serum bottles (Fig. 2). Interestingly, all QssR-deficient mutant strains, $\Delta R 1, \Delta R 2, \Delta R 3$, and $\Delta R 5$, as well as N1-4-dcas9$\mathrm{R} 4$ (with a strong repression in qss 4 expression), exhibited so-called "acid crash" with negligible solvent 
production (Fig. 2a, c, e, f) [28]. The mutant strains grew well at the beginning of the fermentation and exhibited similar growth and acidogenesis profiles compared to the WT strain. However, the mutant strains failed to switch to solventogenesis. Consequently, acids were not efficiently re-assimilated and accumulated to high levels in the medium, leading to severe inhibition on cell growth and unsuccessful solvent production.

For the complementation strain, $\Delta \mathrm{R} 3-\mathrm{R} 3$ exhibited similar profiles as the control for acid
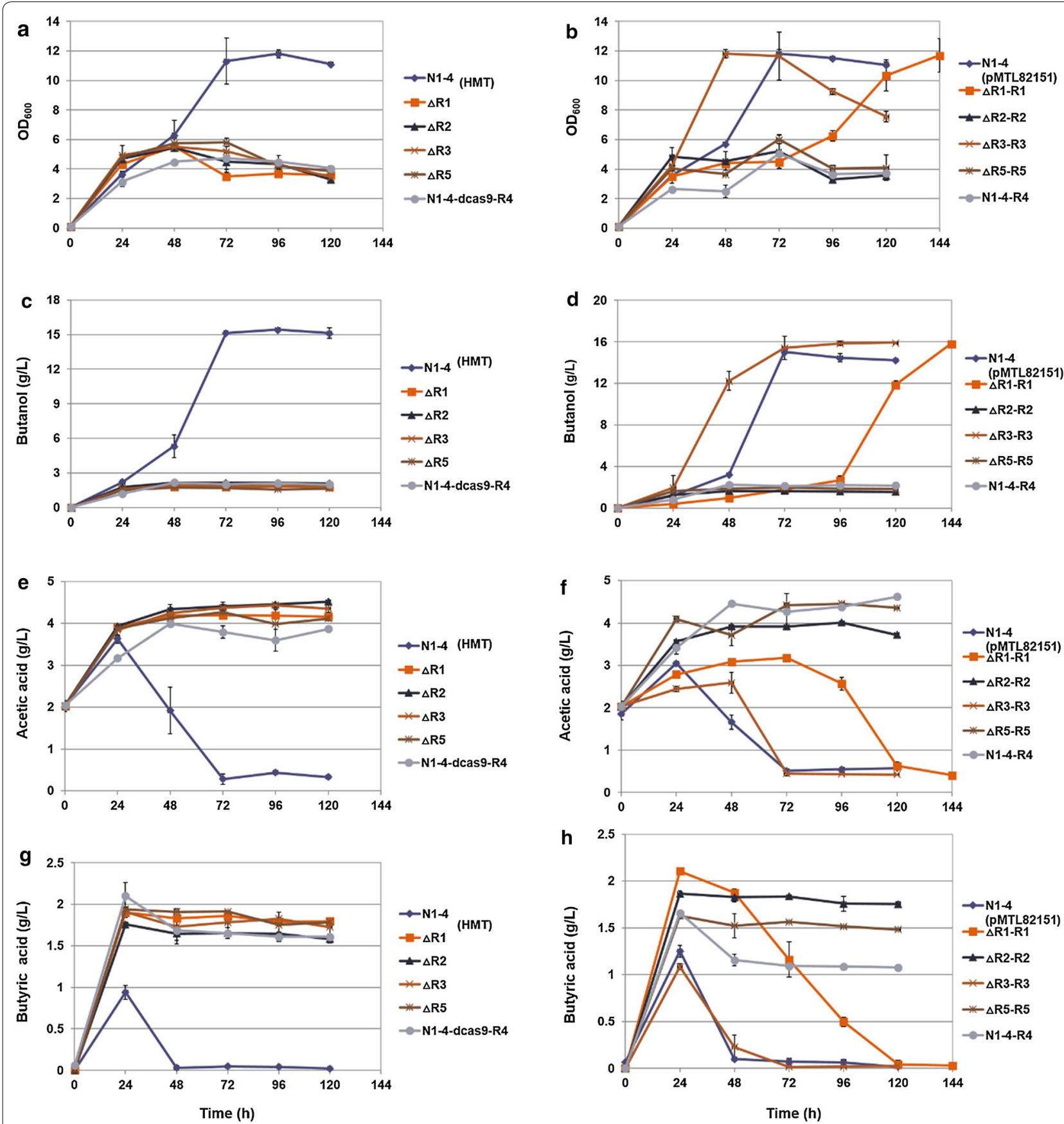

Fig. 2 Fermentation results in small-scale serum bottles with Clostridium saccharoperbutylacetonicum N1-4 (HMT) and various mutant strains. Left panel (a, $\mathbf{c}$, e and $\mathbf{g}$ ): results for $\Delta R 1, \Delta R 2, \Delta R 3, \Delta R 5, N 1$-4-dcas9-R4 as compared to the WT N1-4 (HMT). Right panel (b, $\mathbf{d}$, $\mathbf{f}$ and $\mathbf{h}$ ): results for $\Delta R 1-R 1$, $\triangle R 2-R 2, \Delta R 3-R 3, \Delta R 5-R 5, N 1-4-R 4$ as compared to N1-4 (pMTL82151). a, b Cell growth profiles; $\mathbf{c}, \mathbf{d}$ butanol; e, $\mathbf{f}$ acetic acid; $\mathbf{g}, \mathbf{h}$ butyric acid. The reported value is mean $\pm \mathrm{SD}$ 
production, reassimilation, and solvent production. The N1-4(pMTL82151) strain served as the control for the fermentation. Cell growth in $\Delta$ R3-R3 was even slightly faster than the N1-4(pMTL82151) control; and final butanol production was slightly higher than the control, as well (Fig. 2b, d, f, h). In addition, $\Delta$ R1-R1 exhibited delayed profiles compared to the control for cell growth, acid reassimilation, and butanol production. However, by the end of the fermentation it reached similar levels as the control for maximum cell optical density and butanol production, although this took a much longer time. However, other complementation mutants, including $\Delta R 2-R 2$ and $\Delta \mathrm{R} 5-\mathrm{R} 5$, as well as N1-4-R4 (with the overexpression of qssR4 in WT), showed acid crash phenomenon similar to QssR-deficient mutants (Fig. 2b, d, f, h).

To prevent acid crash caused by acid accumulation in the medium, we subsequently performed the fermentation in $500-\mathrm{mL}, \mathrm{pH}$-controlled bioreactors $(\mathrm{pH} \geq 5.0)$. Initially, we started the fermentation with $5 \%(\mathrm{v} / \mathrm{v})$ inoculation using the preculture of $\mathrm{OD}_{600}=\sim 0.8$. However, the mutant strains did not grow well. Consequently, $\mathrm{OD}_{600}$ of the inoculum preculture was raised to $\sim 1.2$ before fermentation. As shown in Fig. 3(left panel), compared to fermentation in the serum bottle, fermentation in the bioreactor improved significantly. Although most of the QssR-deficient mutants demonstrated slightly inferior capability for acid reassimilation than the control, each re-assimilated acids adequately and produced similar levels of butanol. In fact, the $\Delta R 5$ strain produced slightly higher levels of butanol than the control. The N1-4-dcas9-R4 strain demonstrated a delayed metabolism compared to the control, with cell growth, acid production and reassimilation, and butanol production all slower. However, by the end of the fermentation, the N1-4-dcas9-R4 strain produced approximately the same amount of butanol as the control.

On the other hand, when fermentation with the complementation strain is compared to the control N1-4(pMTL8215), $\Delta \mathrm{R} 1-\mathrm{R} 1$ had delayed and inhibited cell growth, as well as lesser capability for acid reassimilation and much delayed butanol production (right panel in Fig. 3). However, by the end of the fermentation $(>96 \mathrm{~h})$, the strain produced a level of butanol similar to the control. The $\Delta \mathrm{R} 2-\mathrm{R} 2$ stain had $46 \%$ less cell growth than the control, diminished acetate reassimilation (interestingly, the generated butyrate was efficiently re-assimilated), and decreased butanol production (25\% less than the control). $\Delta$ R3-R3 and $\Delta$ R5-R5 exhibited similar cell growth and butanol production (both production rate and level) as the control. The N1-4-R4 strain (with the overexpression of R4) exhibited decreased cell growth and lesser capability for acid reassimilation; and its butanol production was also delayed. Nevertheless, by the end of fermentation, the N1-4-R4 strain achieved a maximum level similar to the control (although it took about $24 \mathrm{~h}$ longer). Further, we observed that it was difficult to cultivate the N1-4-dcas9-R4 strain with an inoculation ratio of $5 \%$ in TGY medium, so we had to increase the inoculation ratio for the cultivation to $10 \%$. Above these observations suggest that qssR4 is essential for C. saccharoperbutylacetonicum, and that a strict control of qssR4 expression at the appropriate level is crucial for normal cell metabolism.

The sol operon plays essential roles in the clostridial solventogenesis $[29,30]$. This operon should be appropriately induced and expressed when cell metabolism shifts from acidogenesis to solventogenesis [31, 32]. The sol operon in N1-4 (HMT) consists of four genes in the order of bld, ctfA, ctfB and adc (Fig. 4). Kosaka and coworkers [5] reported that the sol operon in C. saccharoperbutylacetonicum was transcribed in a polycistronic manner and controlled by two promoters; and that the sol operon is highly expressed during solventogenesis. They also showed that the transcriptional repression of sol operon impaired solvent production in a degenerated strain DGN3-4 derived from N1-4; and the addition of substance extracted from the WT N1-4 culture supernatant could induce both sol operon expression and solvent production. Thus, they inferred that the transcription of the sol operon might be controlled by a QSS [5].

In this study, we examined the transcription of the sol operon in mutant strains compared to that in the WT. Cell culture was harvested from the fermentation in the serum bottle, and transcription levels were measured using qRT-PCR. Results indicate that the expression of the sol operon in $\Delta \mathrm{R} 1, \Delta \mathrm{R} 2, \Delta \mathrm{R} 3, \Delta \mathrm{R} 5, \Delta \mathrm{R} 2-\mathrm{R} 2$, and $\Delta \mathrm{R} 5$ R5 were all repressed by $>50 \%$ compared to N1-4 (HMT) (Fig. 4b), and all these strains exhibited acid crash in the serum-bottle fermentation (Fig. 2). The expression of sol operon in $\Delta \mathrm{R} 3-\mathrm{R} 3$ was comparable with that in the WT. Correspondingly, solvent production level and kinetics in $\Delta$ R3-R3 were similar to the WT (Fig. 2d). The $\Delta$ R1-R1 strain exhibited a $36 \%$ decrease in its sol operon transcription (Fig. 4), which is consistent with fermentation results indicating that acid reassimilation and solvent production were delayed in $\Delta \mathrm{R} 1-\mathrm{R} 1$ compared to the control (Fig. 2d, f, h). Above results suggest that expression of the sol operon is essential for acid reassimilation and solvent production in C. saccharoperbutylacetonicum. The RRNPP-type QSS regulators, including QssR1, QssR2, QssR3, and QssR5, correlate and regulate the appropriate expression of the sol operon. Interestingly, as demonstrated above, using seed culture of higher cell density or controlling $\mathrm{pH}$ to prevent acid crash, we can improve cell growth and restore acid reassimilation and solventogenesis in the mutants (Fig. 3). This indicates that 

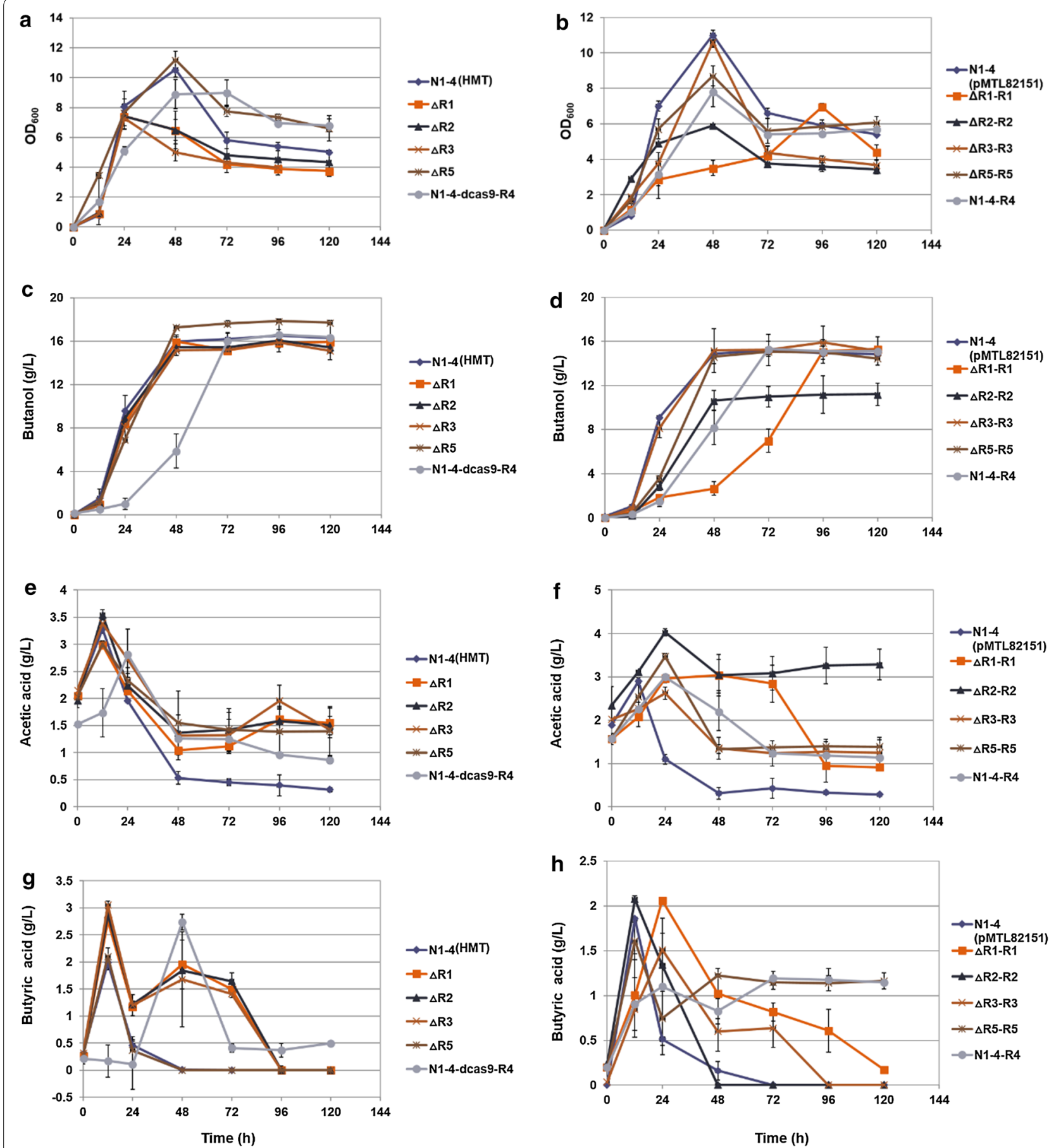

Fig. 3 Fermentation results in 500-mL bioreactors with pH control using Clostridium saccharoperbutylacetonicum N1-4 (HMT) and various mutant strains. Left panels (a, c, e and $\mathbf{g}$ ): results for $\triangle R 1, \Delta R 2, \triangle R 3, \Delta R 5, N 1-4$-dcas9-R4 as compared to the WT N1-4 (HMT). Right panels (b, d, $\mathbf{f}$ and $\mathbf{h}$ ): results for $\triangle R 1-R 1, \triangle R 2-R 2, \triangle R 3-R 3, \triangle R 5-R 5, N 1-4-R 4$ as compared to N1-4 (pMTL82151). a, b Cell growth profiles; $\mathbf{c}, \mathbf{d}$ butanol; $\mathbf{e}, \mathbf{f}$ acetic acid; $\mathbf{g}, \mathbf{h}$ butyric acid. The reported value is mean \pm SD

the deletion of only one of the RRNPP-type regulators (either QssR1, QssR2, QssR3, or QssR5) would impair, but not completely eliminate, the cell capability for acid reassimilation and solvent production. Thus, we infer that the four regulators mentioned above might have a 

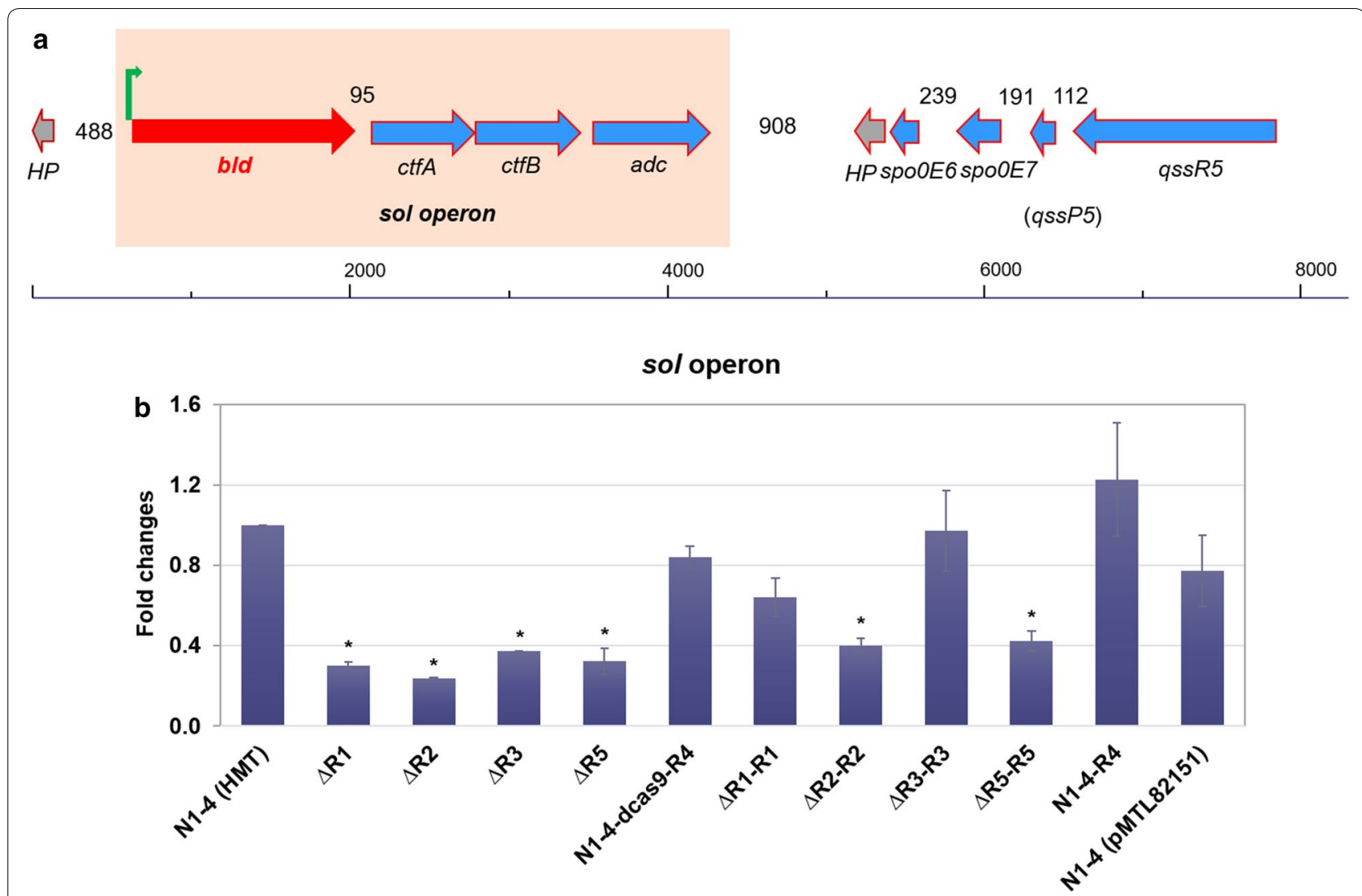

Fig. 4 Schematic representation of the C. saccharoperbutylacetonicum N1-4 (HMT) genomic region comprising both the sol operon (shown within a rectangle) and QSS5 genes (a) and transcriptional analyses of the sol operon (bld was used for the qRT-PCR test as a representative) in N1-4 (HMT) and various mutants (b). Gene names are the following: bld, butyraldehyde dehydrogenase (Cspa_c56880); ctfA, butyrate-acetoacetate CoA-transferase subunit A (Cspa_c56890); ctfB, butyrate-acetoacetate CoA-transferase subunit B (Cspa_c56900); adc, acetoacetate decarboxylase (Cspa_c56910); other gene names as shown in Fig. 1. Bacterial RNAs were extracted from the cell culture after $24 \mathrm{~h}$ cultivation in P2 medium. The reported value is mean $\pm S D$. The asterisk indicates that the corresponding gene expression level in that particular strain was significantly different from the WT strain $(P<0.05)$

synergistic effect on induction of the sol operon expression for acid reassimilation and solvent production.

On the other hand, expression of the sol operon in N1-4-dcas9-R4 and N1-4-R4 is at a level similar and slightly higher (by 23\%), respectively, than in WT. However, these two strains still exhibited 'acid crash' in the fermentation. Therefore, we conclude that the Qss4 system might not directly regulate the expression of the $\mathrm{sol}$ operon, rather, it might be essential for other key cell metabolism. Thus, either the repression or overexpression of the qssR4 gene could impair cell regular metabolism for acid reassimilation and solvent production.

\section{RRNPP-type QSSs regulate cell motility}

Cell motility assays were performed using soft agar plates. As shown in Fig. 5, the WT strain had two different phenotypes: one had no cell motility (N1-4 (HMT)), while the other one showed a little bit cell motility $\left(\mathrm{N} 1-4 \quad(\mathrm{HMT})^{\sharp}\right)$. Herman and co-workers observed three distinct colony morphologies from the same stock of N1-4 (HMT): type I, type R and type S. Type R can change to type I at high frequency and unpredictability, and thus authors predicted that the phenotype conversion might be caused by unclear epigenetic influences [33]. Consequently, we suggest that different cell motility phenotypes from the WT strain are related to their subtype conversions. However, the other control strain of this study, N1-4 (pMTL82151), showed no cell motility at all. All the mutant strains except for N1-4-dcas9R4 exhibited between a 1.7 -fold to 5.0 -fold increase in cell motility compared to the control N1-4 (HMT) and N1-4 (HMT) ${ }^{\#}$, respectively (expressed as the diameter of a swarm 'circle' of migrating cells on the plate). Although the cell migration of N1-4-dcas9-R4 was higher than the control strain N1-4 (HMT), cell motility appeared comparable to that of the N1-4 (HMT) ${ }^{\#}$ strain with only slight cell migration observed. 

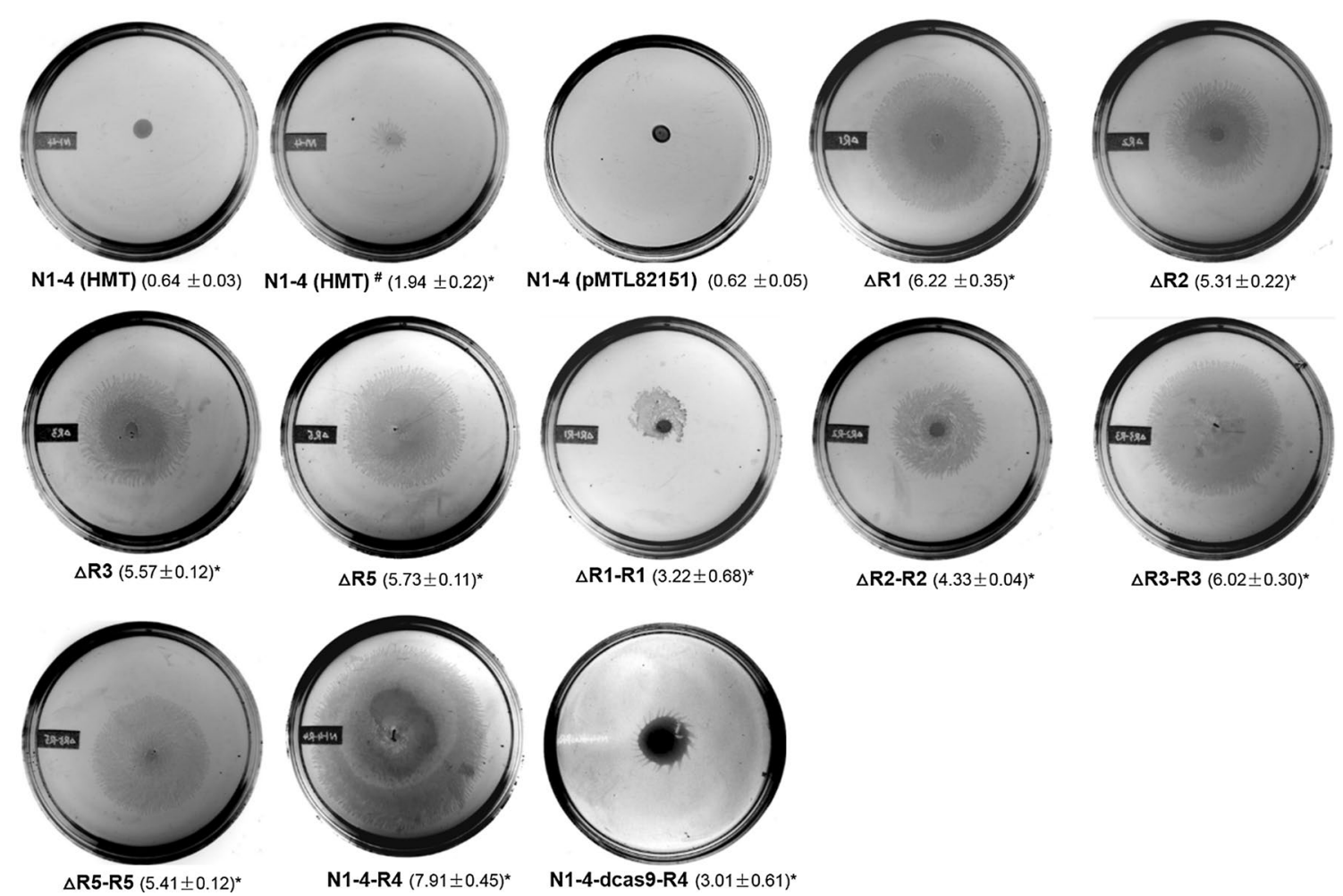

Fig. 5 The cell motility in Clostridium saccharoperbutylacetonicum N1-4 (HMT) and various mutants, represented by the diameter of cell migration on soft agar plates. The WT N1-4 (HMT) strain demonstrated two different motility sizes: N1-4 (HMT) and N1-4 (HMT)\#. The cell culture was grown in TGY medium until the $\mathrm{OD}_{600}$ reached $\sim 0.8$. Two microliters of the cell culture was spotted onto the center of the TGY plate containing $0.5 \%$ agar. The diameter of the cell migration was measured after $12 \mathrm{~h}$ of cultivation at $35^{\circ} \mathrm{C}$ anaerobically. The reported value (the value in the parentheses underneath of each plate image, in centimeter) is mean \pm SD. The asterisk indicates that the corresponding cell motility of that particular strain was significantly different from the WT strain $(P<0.05)$

Bacterial flagella are motility organelles for cell locomotion [34, 35]. Nearly 50 genes control the formation, regulation and function of these flagella [36-38]. Almost half of these genes contribute to the physical structure of the flagella, whereas other genes have regulatory or auxiliary functions [36]. Figure 6a shows the genomic organization of the large gene cluster associated with flagellar synthesis in strain N1-4 (HMT), where 30 genes make up ten putative operons. To elucidate the regulation of these flagellum genes as related to RRNPP-type QSSs, two genes, $\mathrm{flgC}$ (Cspa_c45240) and fliA (Cspa_c45030), were selected and their expression levels quantified with qRT-PCR. It has been reported that $f l g C$ encodes the flagellar basalbody rod protein; while fliA encodes for the alternative RNA polymerase sigma factor (FliA/FlgM-family), assumed to positively regulate the flagellar synthesis [39]. Transcriptional activity of both fliA (Fig. 6b) and $f l g C$ (Fig. 6c) in all mutant strains (including both the QssR-deficient strains and their complementation strains) were $>70 \%$ higher than WT N1-4 (HMT), except for the $f l g C$ gene in N1-4-dcas9-R4 (with a suppressed qss4) which showed a nearly $60 \%$ decrease of expression when compared to the WT. Although the transcription levels of $f l i A$ and $f l g C$ are not perfectly consistent with corresponding cell motility as demonstrated in soft agar plating assays, the general trends were agreeable (Figs. 5 and 6). Overall, results indicated that the upregulation of $f l i A$ and $f l g C$ in most of the mutants would lead to augmented synthesis of flagella and thereby increased cell motility. The transcription levels of $f l i A$ and $f l g C$ in $\Delta \mathrm{R} 1-\mathrm{R} 1$ increased by 21 -fold and 82-fold above the WT, respectively. However, the cell motility of $\Delta R 1-R 1$ appeared impaired and exhibited an irregular shaped cell swarm compared to $\Delta \mathrm{R} 1$. We deduce that the overexpression of qssR1 might have disturbed the tightly controlled flagellar synthesis, which resulted in an irregular shaped cell motility. The transcription level of $f l i A$ in N1-4-dcas9-R4 was 38\% higher than that of the WT, while expression of $f l g C$ was $59 \%$ lower than the WT. Considering cell motility results with respect to the expression levels of $f l i A$ and $f l i C$ in both N1-4-dcas9-R4 and N1-4-R4 strains, we 

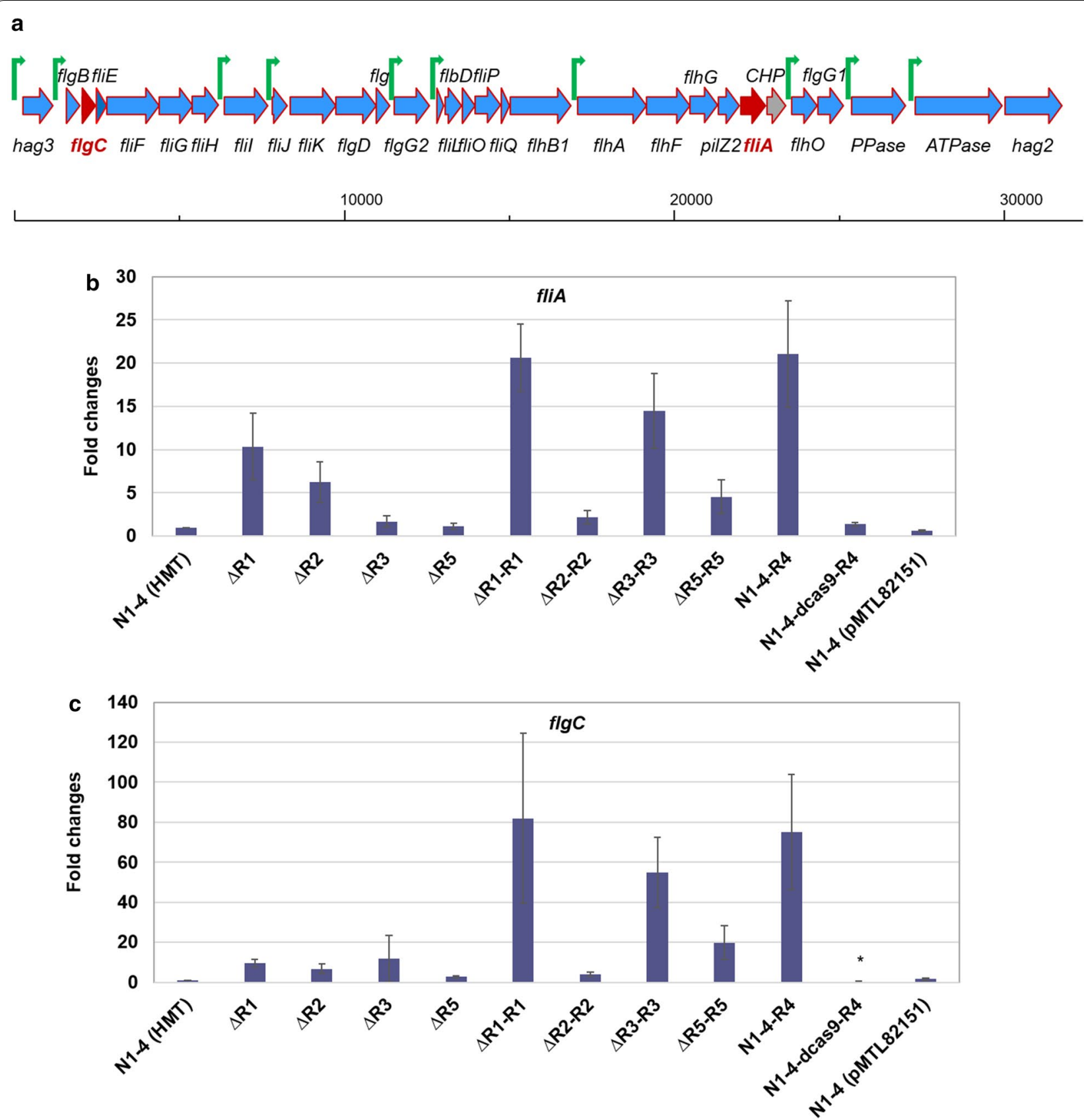

Fig. 6 Schematic representation of the Clostridium saccharoperbutylacetonicum N1-4 (HMT) genomic region comprising genes (from Cspa_ c45260/hag3 to Cspa_c44960/hag2) of the flagellar regulon; flgC and fliA genes are shown in red (a) and transcriptional analyses of fliA (b) and flgC (c) using qRT-PCR in N1-4 (HMT) and various QSS mutants. RNA samples were extracted from the cell culture after $12 \mathrm{~h}$ cultivation in TGY medium. The reported value is mean \pm SD. The asterisk indicates that the corresponding gene expression level in that particular strain was significantly different from the WT strain $(P<0.05)$. Green upwards arrows with tip rightwards $(\mathbf{a})$ indicate promoters of the predicted operons

tentatively conclude that the QSS4 system might have positive effects on flagella synthesis and cell motility.

As demonstrated in $\Delta \mathrm{R} 1, \Delta \mathrm{R} 2, \Delta \mathrm{R} 3$ and $\Delta \mathrm{R} 5$, the deletion of any qssR gene increased cell motility (Fig. 5) as well as expression levels of both $f l i A$ and $f l g C$ (Fig. 6b, c). Exceptionally, the increase of expression of $f l i A$ and flgC in mutant $\Delta \mathrm{R} 5$ was only $14 \%$ and $170 \%$, respectively, which was much less remarkable than upregulation of 
these genes in other strains. Therefore, it appears that deleting $q s s R$ genes leads to upregulation of flagellar synthesis. Nevertheless, the simultaneous increase in cell motility and expression levels of both $f l i A$ and $f l g C$ in corresponding complementation strains $\Delta R 1-R 1$, $\Delta R 2-R 2, \Delta R 3-R 3$ and $\Delta R 5-R 5$ have also been observed. Because this result appears contradictory, we additionally quantified the expression levels of qssR1, qssR2, qssR3 and $q s s R 5$ (Additional file 1: Figure S4) as well as those of qssP1, qssP2, qssP3 and qssP5 (Additional file 1: Figure S6). These experiments were completed using TGY medium in all strains (obviously, expression of a given $q s s R$ gene could not be measured in its cognate QssRdeficient strain because of a complete deletion of this gene). Results indicate that expression levels of $q s s R 1$, $q s s R 2$, and qssR5 in complementation strains $\Delta \mathrm{R} 1-\mathrm{R} 1$, $\Delta R 2-R 2$ and $\Delta R 5-R 5$ were all significantly higher than the control (Additional file 1: Figure S4a, b) and RRNPP-type QSS consists of two proteins: the transcriptional regulator and its cognate signaling peptide precursor [13]. The intact function of the RRNPP-type QSS relies on the role of both parts. The change of expression levels in either could influence the regulation of the target genes. In $\triangle \mathrm{R} 1-\mathrm{R} 1, \Delta \mathrm{R} 2-\mathrm{R} 2$ and $\triangle \mathrm{R} 5-\mathrm{R} 5$, transcription levels of all corresponding qssP1, qssP2 and qssP5 decreased compared to the WT strain, while in $\Delta \mathrm{R} 3-\mathrm{R} 3$, expression levels of qssR3 decreased significantly more than the control (Additional file 1: Figure S3c). Such repression in qssP1, $q s s P 2$, and $q s s P 5$, as well as qssR3, within these host strains could lead to malfunction of the corresponding RRNPP-type QS system. Thus, complementation strains $\Delta \mathrm{R} 1-\mathrm{R} 1, \Delta \mathrm{R} 2-\mathrm{R} 2, \Delta \mathrm{R} 3-\mathrm{R} 3$ and $\Delta \mathrm{R} 5-\mathrm{R} 5$ all exhibited similar increase in cell motility (Fig. 5). In conclusion, the QSS1, QSS2, QSS3 and QSS5 likely negatively regulate cell motility, while it appears that QSS4 positively regulates cell motility in C. saccharoperbutylacetonicum.

\section{RRNPP-type QSSs regulate the cell sporulation}

RRNPP-type QSSs are reported to regulate the sporulation in Bacillus species and C. difficile [40-42]. The Rap and NprR proteins in Bacillus species can directly bind and dephosphorylate SpoOF, which is an intermediate phosphotransfer protein in the sporulation phosphorelay [42]. The sporulation phosphorelay thereafter modulates the phosphorylation state of Spo0A (the master regulator for sporulation), repressing cell sporulation [40]. However, contrary results have been observed in C. difficile in that the RstA (Rap-like protein) could actually enhance cell sporulation [40].

Five of the seven spoOE-like genes in C. saccharoperbutylacetonicum N1-4 (HMT) are located immediately downstream of the genes encoding QSS1, QSS2, and QSS5. Therefore, we hypothesize that the above QSSs might be involved in the regulation of cell sporulation. It is known that $\mathrm{SpoOE}$ is an aspartyl-phosphate phosphatase which specifically dephosphorylates the sporulation transcription factor SpoOA-P and negatively regulates the sporulation initiation pathway in order to control sporulation timing [43]. To test this hypothesis, sporulation efficiency and transcription level of spoOA in all strains (Cspa_c27540) was quantified (Fig. 7). We observed that the 'empty' pMTL82151 plasmid significantly repressed sporulation. Thus for sporulation in $\Delta \mathrm{R} 1, \Delta \mathrm{R} 2, \Delta \mathrm{R} 3, \Delta \mathrm{R} 5$ and N1-4-dcas9-R4, we used N1-4 (HMT) as the control, while for sporulation in $\Delta R 1-R 1$, $\Delta R 2-R 2, \Delta R 3-R 3, \Delta R 5-R 5$ and N1-4-R4, we used N1-4 (pMTL82151) as the control. Results indicate that $\Delta \mathrm{R} 3$ and $\Delta \mathrm{R} 5$ had significantly decreased sporulation efficiency compared to the N1-4 (HMT) strain. Corresponding complementation strains $\Delta \mathrm{R} 3-\mathrm{R} 3$ and $\Delta \mathrm{R} 5-\mathrm{R} 5$ had increased sporulation efficiencies compared to the N1-4 (pMTL82151) strain (Fig. 7a). Expression levels of spoOA in $\Delta \mathrm{R} 3$ and $\Delta \mathrm{R} 5$ were lower (by $37 \%$ and $22 \%$, respectively) than that of the N1-4 (HMT) strain (Fig. 7b), which was consistent with sporulation efficiency results in these strains (Fig. 7b). The expression level of spoOA in $\triangle \mathrm{R} 5$-R5 was 1.65 -fold higher than that of the N1-4 (pMTL82151) strain, while the expression level of spoOA in $\triangle \mathrm{R} 3-\mathrm{R} 3$ was comparable with N1-4 (pMTL82151) strain (2.67 vs 2.54). Overall, we concluded that QSS3 and QSS5 systems positively regulate sporulation; hence, the deletion of $q s s R 3$ or qssR5 lowered sporulation efficiency while the overexpression of them resulted in increased sporulation efficiency (although the expression level of spoOA in $\triangle \mathrm{R} 3-\mathrm{R} 3$ did not demonstrate a corresponding significant increase). These results are similar to the case of $C$. difficile in which RstA protein positively regulates sporulation [40].

$\Delta R 1$ and $\Delta R 2$ strains were observed to have a slight increase in their sporulation efficiency and spoOA expression. Their complementation mutants $\Delta \mathrm{R} 1-\mathrm{R} 1$ and $\Delta \mathrm{R} 2-$ $\mathrm{R} 2$ demonstrated minor increase in sporulation efficiency and significantly higher spoOA expression levels compared to the control (Fig. 7). Unlike gene expression changes in TGY and P2 mediums, the gene expressions of $q s s P 1$ and $q s s P 2$ from $\Delta \mathrm{R} 1-\mathrm{R} 1$ and $\Delta \mathrm{R} 2-\mathrm{R} 2$ in the PG medium were all significantly improved (Additional file 1: Figures S6-S8). Combined with the enhancement of qssR1 and qssR2 (Additional file 1: Figure S5), we conclude that the QSS1 and QSS2 were enhanced in both the $\Delta R 1-R 1$ and $\Delta R 2-R 2$ strains. Both the repression (through the deletion of the regulator gene) and the enhancement (through plasmid-based complementation) of QSS1 and QSS2 demonstrated similar results in terms of the cell sporulation efficiency. Thus, we were not able to draw a definitive conclusion concerning the regulation 


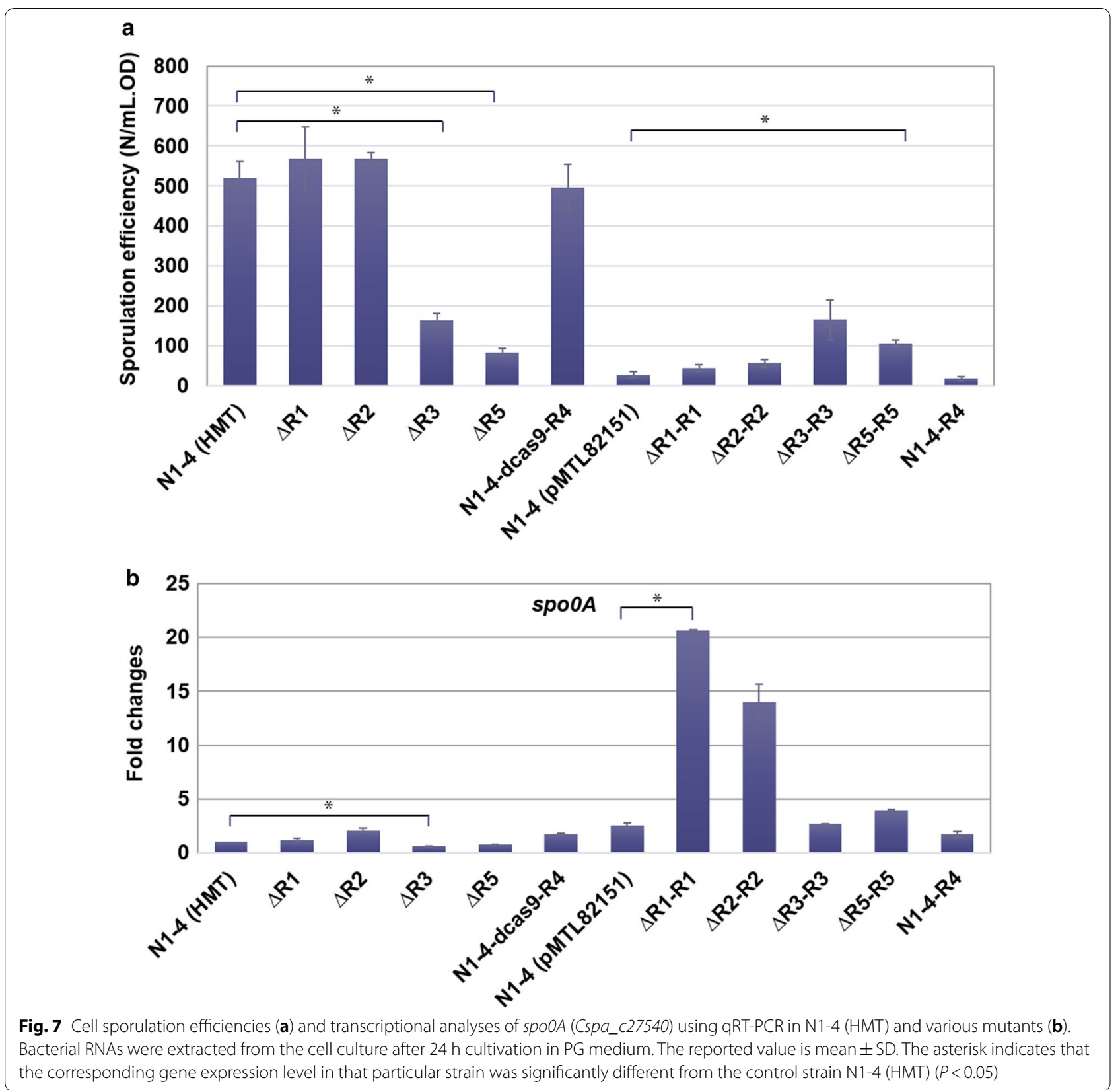

effect of QSS1 and QSS2 on cell sporulation. The expression level of spoOA significantly increased in both $\triangle \mathrm{R} 1-$ $\mathrm{R} 1$ and $\Delta \mathrm{R} 2-\mathrm{R} 2$ while their sporulation efficiency showed only marginal improvement compared with the control N1-4 (pMTL82151). This result might be related to the significant upregulation of spoOE-like genes located downstream of the QSS1, QSS2 and QSS5 operons (Additional file 1: Figure S9). Spo0E has been reported to be involved in the dephosphorylation of SpoOA and is thus a negative regulator of cell sporulation [43]. The elevated expression of $s p o O E 1$ and spoOE 3 in $\triangle \mathrm{R} 1-\Delta \mathrm{R} 1$ and $\Delta \mathrm{R} 2-\Delta \mathrm{R} 2$ might have intensified the dephosphorylation of SpoOA $\sim \mathrm{P}$ and thus did not result in a significantly increased sporulation efficiency (although the expression level of $s p o 0 A$ has been significantly elevated in both strains).

There were no significant changes in spoOA expression or sporulation efficiency in either N1-4-dcas9-R4 or N1-4-R4 when compared to the control N1-4 (HMT) or N1-4 (pMTL82151), respectively (Fig. 7). Therefore, QSS4 likely has no significant regulatory effect on cell sporulation. 
Interestingly, we observed that in N1-4 (pMTL82151) the expression level of all three spoOE-like genes decreased and that of spoOA increased (Fig. 7 and Additional file 1: Figure S9). As described above, Spo0E phosphatase could negatively regulate the activity of SpoOA, the master regulator which should positively regulate the sporulation. The sporulation efficiency in N1-4 (pMTL82151) strain should be higher than the WT N1-4 (HMT) strain, based on above data. However, sporulation efficiency in N1-4 (pMTL82151) decreased significantly compared to the N1-4 (HMT) strain (Fig. 7). In fact, sporulation efficiencies in all strains bearing pMTL82151 or its derivate plasmid decreased remarkably. We speculate that the addition of antibiotics (particularly $15 \mu \mathrm{g} / \mathrm{mL}$ thiamphenicol) may have resulted in this phenomenon.

\section{Conclusions}

This is the first report concerning the RRNPP-type QSSs in C. saccharoperbutylacetonicum N1-4 (HMT). Results indicate that RRNPP-type QS systems play significant roles in the regulation of solvent formation, cell motility and sporulation. We observed that QSS1, QSS2, QSS3, and QSS5 positively regulate the sol operon expression and thus solvent production, but likely negatively regulate cell motility. QSS4 might not directly regulate solvent production, but positively affects cell migration. In addition, QSS3 and QSS5 appear to positively regulate sporulation efficiency. Our study provides original insights into the possible roles of multiple RRNPP-type QSSs of C. saccharoperbutylacetonicum for the regulation of cell metabolism.

\section{Materials and methods}

\section{Microorganisms and cultivation conditions}

All the strains and plasmids used in this study are listed and described in Table 1. C. saccharoperbutylacetonicum N1-4 (HMT) (DSM 14923, = ATCC 27021) was obtained from DSMZ, Germany. For routine cultivation, all C. saccharoperbutylacetonicum strains (both WT and mutants) were grown in an anaerobic chamber $\left(\mathrm{N}_{2}-\mathrm{CO}_{2}-\mathrm{H}_{2}\right.$ with a volume ratio of $85: 10: 5)$ at $35{ }^{\circ} \mathrm{C}$ in tryptone-glucose-yeast extract (TGY) medium [44]. When needed, clarithromycin (Cla) and thiamphenicol (Tm) were added into the TGY medium to a final concentration of $30 \mu \mathrm{g} /$ $\mathrm{mL}$ and $15 \mu \mathrm{g} / \mathrm{mL}$, respectively. Escherichia coli $\mathrm{DH} 5 \alpha$ were used for routine plasmid propagation and maintenance. It was grown aerobically at $37^{\circ} \mathrm{C}$ in Luria-Bertani (LB) medium supplemented with $100 \mu \mathrm{g} / \mathrm{mL}$ of ampicillin (Amp) or $34 \mu \mathrm{g} / \mathrm{mL}$ chloramphenicol $(\mathrm{Cm})$, as needed.

\section{Mutant construction}

In this study, the RRNPP-type regulator genes Cspa c00280,Cspa_c21720,Cspa_c27220,Cspa_c29260 and
Cspa_c56960 were named as qssR1, qssR2, qssR3, qssR4 and $q s s R 5$, respectively (Fig. 1); their putative cognate signaling peptide genes Cspa_c00290,Cspa_c21710, Cspa_c27230, Cspa_c29250 and Cspa_c56950 were named as qssP1, qssP2, qssP3, qssP4 and qssP5, respectively (Fig. 1). The mutant with gene deletion was screened as previously described [23]. The final plasmid-free mutant was designated as $C$. saccharoperbutylacetonicum $\Delta \mathrm{R} 1, \Delta \mathrm{R} 2, \Delta \mathrm{R} 3$, and $\Delta \mathrm{R} 5$ (the deletion of qssR 4 was unsuccessful despite numerous attempts). The mutant bearing the corresponding plasmid for complementation purpose was named as $\Delta \mathrm{R} 1-\mathrm{R} 1, \Delta \mathrm{R} 2$ $\mathrm{R} 2, \Delta \mathrm{R} 3-\mathrm{R} 3$, or $\Delta \mathrm{R} 5-\mathrm{R} 5$, respectively. N1-4-R4 is the recombinant strain based on WT holding the plasmid for the overexpression of qssR4. Similarly, N1-4-dcas9$\mathrm{R} 4$ is the recombinant strain based on WT holding the pYW-19d-qssR4 plasmid. Refer to the Additional file 1 for more details about the construction of plasmids and mutants.

\section{Cell motility assay}

Cell culture was grown overnight in TGY medium supplemented with antibiotics when necessary. The culture was then subcultured in fresh medium until $\mathrm{OD}_{600}$ reached $\sim 0.8$. Two microliters of prepared culture was spotted in the center of TGY plates (supplementary with appropriate antibiotics) with $0.5 \%$ agar. The diameter of cell migration was measured after $12 \mathrm{~h}$ of cultivation. Pictures were taken with the AlphaImager ${ }^{\circledR} \mathrm{HP}$ system (Alpha Innotech, USA).

\section{Sporulation assay}

The cell culture was grown in TGY medium until $\mathrm{OD}_{600}$ reached $\sim 0.8$. The seed culture was then inoculated into $20 \mathrm{~mL}$ PG medium (150 g/L mashed potato, $10 \mathrm{~g} / \mathrm{L}$ glucose, $1 \mathrm{~g} / \mathrm{L} \mathrm{NH}_{4} \mathrm{SO}_{4}$ and $3 \mathrm{~g} / \mathrm{L} \mathrm{CaCO}_{3}, \mathrm{pH}$ 6.2) [45] with an inoculation ratio of $5 \%$ and subsequently cultured for 7 days in the anaerobic chamber. The PG medium was filtered by gauze before adding $\mathrm{CaCO}_{3}$. An appropriate amount of $1 \mathrm{~N} \mathrm{HCl}$ was added into the broth to remove remaining $\mathrm{CaCO}_{3}$ after cultivation. $\mathrm{OD}_{600}$ of the cell culture was determined. Then the culture was centrifuged at $4200 \mathrm{~g}$ and $4{ }^{\circ} \mathrm{C}$ for $10 \mathrm{~min}$. The cell pellet was washed for twice with $\mathrm{dd}_{2} \mathrm{O}$ and then resuspended into $1 \mathrm{~mL}$ of $\mathrm{ddH}_{2} \mathrm{O} .100 \mu \mathrm{L}$ of the collected spores was spread onto TGY agar plates after heat treatment $\left(80^{\circ} \mathrm{C}\right.$ for $\left.10 \mathrm{~min}\right)$ [45]. Colonies were counted after the incubation for 2 days in the anaerobic chamber. The sporulation efficiency was calculated as $N /$ mL.OD. $N$ represented the number of colonies. 
Table 1 Strains and plasmids used in this study

\begin{tabular}{|c|c|c|}
\hline Strains and plasmids & Relevant characteristics & Source or reference \\
\hline \multicolumn{3}{|l|}{ Strains } \\
\hline C. saccharoperbutylacetonicum N1-4 (HMT) & N1-4, DSM 14923 (=ATCC 27021), WT strain & DSMZ \\
\hline C. saccharoperbutylacetonicum $\triangle \mathrm{R} 1$ & Derived from N1-4, $\Delta$ Cspa_c00280 & This study \\
\hline C. saccharoperbutylacetonicum $\triangle \mathrm{R} 2$ & Derived from N1-4, $\triangle$ Cspa_c21720 & This study \\
\hline C. saccharoperbutylacetonicum $\triangle R 3$ & Derived from N1-4, $\Delta$ Cspa_c27220 & This study \\
\hline C. saccharoperbutylacetonicum N1-4-dcas9-R4 & N1-4 with the expression of pYW-19d-qssR4 & This study \\
\hline C. saccharoperbutylacetonicum $\triangle \mathrm{R} 5$ & Derived from N1-4, $\Delta$ Cspa_c56960 & This study \\
\hline C. saccharoperbutylacetonicum $\triangle \mathrm{R} 1-\mathrm{R} 1$ & $\Delta R 1$ strain with the expression of pMTL-qssR1 & This study \\
\hline C. saccharoperbutylacetonicum $\triangle \mathrm{R} 2-\mathrm{R} 2$ & $\Delta R 2$ strain with the expression of pMTL-qssR2 & This study \\
\hline C. saccharoperbutylacetonicum $\triangle \mathrm{R} 3-\mathrm{R} 3$ & $\Delta R 3$ strain with the expression of pMTL-qssR3 & This study \\
\hline C. saccharoperbutylacetonicum N1-4-R4 & N1-4 strain with the expression of pMTL-qssR4 & This study \\
\hline C. saccharoperbutylacetonicum $\triangle \mathrm{R} 5-\mathrm{R} 5$ & $\Delta R 5$ strain with the expression of pMTL-qssR5 & This study \\
\hline C. saccharoperbutylacetonicum N1-4 (pMTL82151) & N1-4 strain with the expression of pMTL82151 & This study \\
\hline Clostridium tyrobutyricum ATCC 25755 & ATCC 25755 (=KCTC 5387) & ATCC \\
\hline E. coli DH5a & $\begin{array}{l}\mathrm{F}^{-}, \varphi 80 \mathrm{~d} / a c Z \Delta \mathrm{M} 1, \triangle\left(\text { lacZYA-argF) } \cup 169 \text {, deoR, recA1, endA1, hsdR17 }\left(\mathrm{r}_{\mathrm{k}}^{-}, \mathrm{m}_{\mathrm{k}}^{+}\right) \text {, }\right. \\
\text { phoA, supE44, } \lambda^{-} \text {thi-1, gyrA96, relA1 }\end{array}$ & NEB \\
\hline \multicolumn{3}{|l|}{ Plasmids } \\
\hline pYW34 & CAK ori, Ampr', Erm', Plac::Cas9, gRNA & [24] \\
\hline pMTL82151 & pBP1 ori, catP, ColE1, tra & [47] \\
\hline pYW19d-BseRI & CAK ori, Ampr ${ }^{r}$ Ermr, Pthl:::dCas9, gRNA & [48] \\
\hline pYW34- $\triangle q s s R 1$ & $\begin{array}{l}\text { Derived from pYW34, J231 19::20-nt gRNA targeting Cspa_c00280, homol- } \\
\text { ogy arms }\end{array}$ & This study \\
\hline pYW34- $\triangle q s s R 2$ & $\begin{array}{l}\text { Derived from pYW34, J23119::20-nt gRNA targeting Cspa_c21720, homol- } \\
\text { ogy arms }\end{array}$ & This study \\
\hline pYW34- $\triangle q s s R 3$ & $\begin{array}{l}\text { Derived from pYW34, J231 19::20-nt gRNA targeting Cspa_c27220, homol- } \\
\text { ogy arms }\end{array}$ & This study \\
\hline pYW34- $\triangle 9 s s R 5$ & $\begin{array}{l}\text { Derived from pYW34, J23119::20-nt gRNA targeting Cspa_c56960, homol- } \\
\text { ogy arms }\end{array}$ & This study \\
\hline pMTL-qssR1 & $\begin{array}{l}\text { Derived from pMTL82151, with the expression of Cspa_c00280 under the } \\
\text { control of cat1 promoter from C. tyrobutyricum ATCC } 25755\end{array}$ & This study \\
\hline pMTL-qssR2 & $\begin{array}{l}\text { Derived from pMTL82151, with the expression of Cspa_c21720 under the } \\
\text { control of cat1 promoter from C. tyrobutyricum ATCC } 25755\end{array}$ & This study \\
\hline pMTL-qssR3 & $\begin{array}{l}\text { Derived from pMTL82151, with the expression of Cspa_c27220 under the } \\
\text { control of cat1 promoter from C. tyrobutyricum ATCC } 25755\end{array}$ & This study \\
\hline pMTL-qssR4 & $\begin{array}{l}\text { Derived from pMTL82151, with the expression of Cspa_c29260 under the } \\
\text { control of cat1 promoter from C. tyrobutyricum ATCC } 25755\end{array}$ & This study \\
\hline pMTL-qssR5 & $\begin{array}{l}\text { Derived from pMTL82151, with the expression of Cspa_c56960 under the } \\
\text { control of cat1 promoter from C. tyrobutyricum ATCC } 25755\end{array}$ & This study \\
\hline pYW19d-qssR4 & $\begin{array}{l}\text { Derived from pYW19d-BseRl, with J23119::20-nt gRNA targeting Cspa_ } \\
\text { c29260 }\end{array}$ & This study \\
\hline
\end{tabular}

\section{Fermentation}

The ABE fermentation was performed in either serum bottles or $500-\mathrm{mL}$ bioreactors. For serum bottle fermentation, cell culture was cultivated in TGY medium in the anaerobic chamber until $\mathrm{OD}_{600}$ reached $\sim 0.8$. The seed culture was then inoculated into $100 \mathrm{~mL}$ of P2 medium (80 g/L glucose, $2 \mathrm{~g} / \mathrm{L}$ yeast extract, and $6 \mathrm{~g} / \mathrm{L}$ tryptone) in a $250-\mathrm{mL}$ bottle with an inoculation ratio of $5 \%$. Fermentation was performed under anaerobic conditions at $30{ }^{\circ} \mathrm{C}$ with an agitation of $150 \mathrm{rpm}$. Analytical samples were taken every $24 \mathrm{~h}$. For bioreactor fermentation, the cell culture was cultivated in TGY medium in the anaerobic chamber until $\mathrm{OD}_{600}$ reached $\sim 1.2$. Thereafter, the seed culture was inoculated into $300 \mathrm{~mL}$ of P2 medium (80 g/L glucose, $2 \mathrm{~g} / \mathrm{L}$ yeast extract, and $6 \mathrm{~g} / \mathrm{L}$ tryptone) in 500-mL bioreactors (GS-MFC, Shanghai Gu Xin biological technology Co., Shanghai, China) with an inoculation ratio of $5 \%$. Fermentation was performed at $30{ }^{\circ} \mathrm{C}$ with an agitation of $150 \mathrm{rpm}$, with $\mathrm{pH}$ controlled to $\geq 5.0$ using $3 \mathrm{~N} \mathrm{NaOH}$. Samples were withdrawn for analysis 
every $12 \mathrm{~h}$ in the first $24 \mathrm{~h}$ and every $24 \mathrm{~h}$ afterwards. Appropriate amounts of antibiotics were added into the medium when necessary.

Concentrations of butanol, acetic acid and butyric acid were measured using an Agilent 1260 Infinity HPLC system (Agilent Technologies, Santa Clara, CA) equipped with a refractive index detector (RID), and a Varian MetaCarb 87H column (Agilent Technologies, CA). The column was eluted with $5 \mathrm{mM} \mathrm{H}_{2} \mathrm{SO}_{4}$ with a flow rate of $0.6 \mathrm{~mL} / \mathrm{min}$ at $25^{\circ} \mathrm{C}$ [46].

\section{Supplementary information}

Supplementary information accompanies this paper at https://doi. org/10.1186/s13068-020-01723-x.

Additional file 1: Table S1. Primers used in this study. Table S2. Comparative pair-alignment data of amino acid sequences of the Clostridium saccharoperbutylacetonicum RRNPP-type transcriptional regulators. Table S3. Comparative pair-alignment data of amino acid sequences of the signaling-peptide precursors of the five Clostridium saccharoperbutylacetonicum RRNPP-type quorum sensing systems. Figure S1. Schematic of two rounds of PCR to obtain the DNA fragment containing 20-nt gRNA sequence for constructing the CRISPR-Cas9 plasmid for gene deletion. Figure S2. Confirmation of gene deletion by colony PCR. Figure S3. Transcriptional analyses of qssR1, qssR2, qssR3, qssR4 and qssR5 in wild-type N1-4 (HMT) and relevant mutant strains using qRT-PCR. Figure S4. Transcriptional analyses of qssR1, qssR2, qssR3, qssR4 and qssR5 in wild-type N1-4 (HMT) and relevant mutant strains using qRT-PCR. Figure S5. Transcriptional analyses of qssR1, qssR2, qssR3, qssR4 and qssR5 in wild-type N1-4 (HMT) and relevant mutant strains using qRT-PCR. Figure S6. Transcriptional analyses of qssP1, qssP2, qssP3, qssP4 and qssP5 in wild-type N1-4 (HMT) and relevant mutant strains using qRT-PCR. Figure S7. Transcriptional analyses of qssP1, qssP2, qssP3, qssP4 and qssP5 in wild-type N1-4 (HMT) and relevant mutant strains using qRT-PCR. Figure S8. Transcriptional analyses of qsSP1, qsSP2, qsSP3, qsSP4 and qsSP5 in wildtype N1-4 (HMT) and relevant mutant strains using qRT-PCR. Figure S9. Transcriptional analyses of spoOE-like genes in wild-type N1-4 (HMT) and relevant mutant strains using qRT-PCR.

\section{Abbreviations}

ABE: Acetone-butanol-ethanol; QSSs: Quorum-sensing systems; Opp: Oligopeptide permease; TPRs: Tetratricopeptide repeats; AIP: Auto-inducing peptide; CRISPR: Clustered Regularly Interspaced Short Palindromic Repeats; TGY:Tryptone-glucose-yeast extract; qRT-PCR: Quantitative reverse transcription PCR; CPCR: Colony PCR.

\section{Acknowledgements}

We thank Dr. Hans Blaschek (University of Illinois at Urbana-Champaign) for providing pYW34, and Dr. Nigel Minton (University of Nottingham, UK) for providing pMTL series of plasmids. We also thank Dr. Michael Miller at Auburn University for his technical guidance and assistance with the qRT-PCR experiment.

\section{Authors' contributions}

JF, YW and IB designed the experiments. JF, WZ, PW, ZTZ and YG performed the experiments. JF, YW, IB and MD drafted and revised the manuscript. All authors read and approved the final manuscript.

\section{Funding}

This material is based upon work supported by the U.S. Department of Energy's Office of Energy Efficiency and Renewable Energy (EERE) under the Co-Optima Initiative Award Number DE-EE0008483, the USDA-NIFA Southeastern SunGrant, the Auburn University Intramural Grants Program (IGP), the USDA-NIFA Hatch project (ALA014-1017025), and the Alabama Agricultural Experiment Station. Jun Feng is a Post-doc research fellow supported by the Post-doc fellowship from the Auburn University Hatch program of the USDA-NIFA.

Availability of data and materials

Not applicable.

Ethics approval and consent to participate

Not applicable.

\section{Consent for publication}

All the authors consent to publication.

\section{Competing interests}

The authors declare that they have no competing interests.

\section{Author details}

${ }^{1}$ Department of Biosystems Engineering, Auburn University, 350 Mell Street, Auburn, AL 36849, USA. ${ }^{2}$ School of Engineering, Anhui Agricultural University, Hefei 230036, China. ${ }^{3}$ School of Molecular Cell Biology and Biotechnology, The George S. Wise Faculty of Life Sciences, Tel Aviv University, Ramat Aviv, 6997801 Tel Aviv, Israel. ${ }^{4}$ Center for Bioenergy and Bioproducts, Auburn University, Auburn, AL 36849, USA.

Received: 9 September 2019 Accepted: 30 April 2020

Published online: 08 May 2020

\section{References}

1. Whiteley M, Diggle SP, Greenberg EP. Progress in and promise of bacterial quorum sensing research. Nature. 2017;551(7680):313-20.

2. Fuqua WC, Winans SC, Greenberg EP. Quorum sensing in bacteria: the LuxR-Luxl family of cell density-responsive transcriptional regulators. J Bacteriol. 1994;176(2):269-75.

3. Papenfort K, Bassler BL. Quorum sensing signal-response systems in Gram-negative bacteria. Nat Rev Microbiol. 2016;14(9):576-88.

4. Miller MB, Bassler BL. Quorum sensing in bacteria. Ann Rev Microbiol. 2001;55(1):165-99.

5. Neiditch MB, Capodagli GC, Prehna G, Federle MJ. Genetic and structural analyses of RRNPP intercellular peptide signaling of Gram-positive bacteria. Annu Rev Genet. 2017;51:311-33.

6. Lee J, Jang Y-S, Han M-J, Kim JY, Lee SY. Deciphering Clostridium tyrobutyricum metabolism based on the whole-genome sequence and proteome analyses. MBio. 2016;7(3):e00743-00716.

7. Kosaka T, Nakayama S, Nakaya K, Yoshino S, Furukawa K. Characterization of the sol operon in butanol-hyperproducing Clostridium saccharoperbutylacetonicum strain N1-4 and its degeneration mechanism. Biosci Biotechnol Biochem. 2007;71(1):58-68.

8. Kotte A-K. RNPP-type quorum sensing in Clostridium acetobutylicum. University of Nottingham; 2013.

9. Xue C, Zhao J, Chen L, Yang S-T, Bai F. Recent advances and state-of-theart strategies in strain and process engineering for biobutanol production by Clostridium acetobutylicum. Biotechnol Adv. 2017;35:310-22.

10. Lu C, Yu L, Varghese S, Yu M, Yang S-T. Enhanced robustness in acetonebutanol-ethanol fermentation with engineered Clostridium beijerinckii overexpressing adhE2 and ctfAB. Bioresour Technol. 2017;243:1000-8.

11. Wang S, Dong S, Wang Y. Enhancement of solvent production by overexpressing key genes of the acetone-butanol-ethanol fermentation pathway in Clostridium saccharoperbutylacetonicum N1-4. Bioresour Technol. 2017;245(Pt A):426-33.

12. Steiner E, Scott J, Minton NP, Winzer K. An agr quorum sensing system that regulates granulose formation and sporulation in Clostridium acetobutylicum. Appl Environ Microbiol. 2012;78(4):1113-22.

13. Kotte A-K, Severn O, Bean Z, Schwarz K, Minton NP, Winzer K. RRNPPtype quorum sensing regulates solvent formation and sporulation in Clostridium acetobutylicum. Microbiology. 2020. https://doi.org/10.1099/ mic.0.000916

14. Jabbari S, Steiner E, Heap JT, Winzer K, Minton NP, King JR. The putative influence of the agr operon upon survival mechanisms used by Clostridium acetobutylicum. Math Biosci. 2013;243(2):223-39. 
15. Novick RP, Geisinger E. Quorum sensing in staphylococci. Annu Rev Genet. 2008;42:541-64.

16. Olson ME, Todd DA, Schaeffer CR, Paharik AE, Van Dyke MJ, Büttner H, Dunman PM, Rohde H, Cech NB, Fey PD. Staphylococcus epidermidis agr quorum-sensing system: signal identification, cross talk, and importance in colonization. J Bacteriol. 2014;196(19):3482-93.

17. Queck SY, Jameson-Lee M, Villaruz AE, Bach T-HL, Khan BA, Sturdevant DE, Ricklefs SM, Li M, Otto M. RNAlll-independent target gene control by the agr quorum-sensing system: insight into the evolution of virulence regulation in Staphylococcus aureus. Mol Cell. 2008;32(1):150-8.

18. Do H, Kumaraswami M. Structural mechanisms of peptide recognition and allosteric modulation of gene regulation by the RRNPP family of quorum-sensing regulators. J Mol Biol. 2016;428(14):2793-804.

19. Perez-Pascual D, Monnet V, Gardan R. Bacterial cell-cell communication in the host via RRNPP peptide-binding regulators. Front Microbiol. 2016;7:706.

20. Declerck N, Bouillaut L, Chaix D, Rugani N, Slamti L, Hoh F, Lereclus D, Arold ST. Structure of PICR: insights into virulence regulation and evolution of quorum sensing in Gram-positive bacteria. Proc Natl Acad Sci. 2007:104(47):18490-5.

21. Rocha-Estrada J, Aceves-Diez AE, Guarneros G, de la Torre M. The RNPP family of quorum-sensing proteins in Gram-positive bacteria. Appl Microbiol Biotechnol. 2010;87(3):913-23.

22. Motoyoshi H. Process for producing butanol by fermentation. In: Google patents; 1960

23. Wang S, Dong S, Wang P, Tao Y, Wang Y. Genome editing in Clostridium saccharoperbutylacetonicum N1-4 with the CRISPR-Cas9 system. Appl Environ Microbiol. 2017;83(10):e00233-17.

24. Wang Y, Zhang Z-T, Seo S-O, Lynn P, Lu T, Jin Y-S, Blaschek HP. Bacteria genome editing with CRISPR-Cas9: deletion, integration, single nucleotide modification, and desirable "clean" mutant selection in Clostridium beijerinckii as an example. ACS Synth Biol. 2016;5(7):721-32.

25. Ohlrogge JB, Shine WE, Stumpf P. Fat metabolism in higher plants: characterization of plant acyl-ACP and acyl-CoA hydrolases. Arch Biochem Biophys. 1978;189(2):382-91.

26. Mootz HD, Finking R, Marahiel MA. 4'-Phosphopantetheine transfer in primary and secondary metabolism of Bacillus subtilis. J Biol Chem. 2001;276(40):37289-98.

27. Zhang J, Zong W, Hong W, Zhang Z-T, Wang Y. Exploiting endogenous CRISPR-Cas system for multiplex genome editing in Clostridium tyrobutyricum and engineer the strain for high-level butanol production. Metab Eng. 2018;47:49-59.

28. Maddox I, Steiner E, Hirsch S, Wessner S, Gutierrez N, Gapes J, Schuster K. The cause of "Acid Crash" and "Acidogenic Fermentations" during the batch acetone-butanol-ethanol(ABE-) fermentation process. J Mol Microbiol Biotechnol. 2000;2(1):95-100.

29. Dürre P. New insights and novel developments in clostridial acetone/ butanol/isopropanol fermentation. Appl Microbiol Biotechnol. 1998:49(6):639-48.

30. Jones DT, Woods DR. Acetone-butanol fermentation revisited. Microbio Rev. 1986;50(4):484-524

31. Chen C-K, Blaschek HP. Effect of acetate on molecular and physiological aspects of Clostridium beijerinckii NCIMB 8052 solvent production and strain degeneration. Appl Environ Microbiol. 1999;65(2):499-505.

32. Dürre P, Böhringer M, Nakotte S, Schaffer S, Thormann K, Zickner B. Transcriptional regulation of solventogenesis in Clostridium acetobutylicum. $J$ Mol Microbiol Biotechnol. 2002;4(3):295-300.
33. Herman NA, Li J, Bedi R, Turchi B, Liu X, Miller MJ, Zhang W. Development of a high-efficiency transformation method and implementation of rational metabolic engineering for the industrial butanol hyper-producer Clostridium saccharoperbutylacetonicum strain N1-4. Appl Environ Microbiol. 2017:83:e02942-16.

34. Twine SM, Reid CW, Aubry A, McMullin DR, Fulton KM, Austin J, Logan SM. Motility and flagellar glycosylation in Clostridium difficile. J Bacteriol. 2009;191 (22):7050-62.

35. Pallen MJ, Matzke NJ. From the origin of species to the origin of bacterial flagella. Nat Rev Microbiol. 2006;4(10):784-90.

36. Liu R, Ochman H. Origins of flagellar gene operons and secondary flagellar systems. J Bacteriol. 2007;189(19):7098-104.

37. Macnab RM. Type III flagellar protein export and flagellar assembly. Biochim Biophys Acta Mol Cell Res. 2004;1694(1-3):207-17.

38. Stevenson E, Minton NP, Kuehne SA. The role of flagella in Clostridium difficile pathogenicity. Trends Microbiol. 2015;23(5):275-82.

39. Kutsukake K, lino T. Role of the FliA-FlgM regulatory system on the transcriptional control of the flagellar regulon and flagellar formation in Salmonella typhimurium. J Bacteriol. 1994;176(12):3598-605.

40. Edwards AN, Tamayo R, McBride SM. A novel regulator controls Clostridium difficile sporulation, motility and toxin production. Mol Microbiol. 2016;100(6):954-71.

41. Perego M, Hanstein C, Welsh KM, Djavakhishvili T, Glaser P, Hoch JA. Multiple protein-aspartate phosphatases provide a mechanism for the integration of diverse signals in the control of development in B. subtilis. Cell. 1994;79(6):1047-55.

42. Cabrera R, Rocha J, Flores V, Vázquez-Moreno L, Guarneros G, Olmedo G, Rodríguez-Romero A, de la Torre M. Regulation of sporulation initiation by NprR and its signaling peptide NprRB: molecular recognition and conformational changes. Appl Microbiol Biotechnol. 2014;98(22):9399-412.

43. Diaz AR, Stephenson S, Green JM, Levdikov VM, Wilkinson AJ, Perego M. Functional role for a conserved aspartate in the Spo0E signature motif involved in the dephosphorylation of the Bacillus subtilis sporulation regulator SpoOA. J Biol Chem. 2008;283(5):2962-72.

44. Wang $Y$, Li X, Milne CB, Janssen $H$, Lin W, Phan G, Hu H, Jin Y-S, Price ND, Blaschek HP. Development of a gene knockout system using mobile group II introns (Targetron) and genetic disruption of acid production pathways in Clostridium beijerinckii. Appl Environ Microbiol. 2013;79(19):5853-63.

45. Hongo M, Murata A, Kono K, Kato F. Lysogeny and bacteriocinogeny in strains of Clostridium species. Agric Biol Chem. 1968;32(1):27-33.

46. Yao D, Dong S, Wang P, Chen T, Wang J, Yue Z-B, Wang Y. Robustness of Clostridium saccharoperbutylacetonicum for acetone-butanol-ethanol production: effects of lignocellulosic sugars and inhibitors. Fuel. 2017;208:549-57.

47. Heap JT, Pennington OJ, Cartman ST, Minton NP. A modular system for Clostridium shuttle plasmids. J Microbiol Methods. 2009;78(1):79-85.

48. Wang Y, Zhang ZT, Seo SO, Lynn P, Lu T, Jin YS, Blaschek HP. Gene transcription repression in Clostridium beijerinckii using CRISPR-dCas9. Biotechnol Bioeng. 2016;113(12):2739-43.

\section{Publisher's Note}

Springer Nature remains neutral with regard to jurisdictional claims in published maps and institutional affiliations. 